\title{
Test-taking strategies of Year 5 on Reading Comprehension Test at a Primary Level
}

\author{
Siti Nur'Azmina ${ }^{[1][2]}$, Maslawati Mohamad ${ }^{[2]}$ \\ ${ }^{1}$ SK Penibong, D/A PPD Daro, 96200 Daro, Sarawak \\ ${ }^{2}$ Faculty of Education, Universiti Kebangsaan Malaysia (UKM), 43600 Bangi, Selangor, Malaysia \\ DOI: $10.29322 /$ IJSRP.10.02.2020.p9824 \\ http://dx.doi.org/10.29322/IJSRP.10.02.2020.p9824
}

\begin{abstract}
Test is part of the journey of human life. There are questions, though, as to how people qualify with flying colours and otherwise. This research helps to describe the methods used by Melanau primary pupils to answer to the reading comprehension examination. Based on purposeful selection, 10 pupils were chosen from two different schools to discuss high and low Melanau primary pupils in choosing comprehension test strategies. The research attempts to explore the test-taking techniques used by Melanau for the main use of two forms of English proficiency. Verbal comments from these individuals were collected using the think-aloud protocol and playback sessions. The results provided strategies used by the Melanau primary pupils in answering English comprehension test in high and low proficiency level of pupils and how they arrived their answer. High proficiency pupils have used more strategies than low pupil proficiency. High proficiency Melanau participants used 21 types of strategies, seven more strategies used compared to low proficiency pupils who used 14 types of strategies for reading comprehension exams. In addition, the study provided an overview into the styles of test-taking techniques used by Melanau primary pupils, which can also be used by other English learners to answer to the reading comprehension examination.
\end{abstract}

Index Terms- Reading comprehension test, Melanau, test-taking strategies, think-aloud protocol.

\section{INTRODUCTION}

ccording to McNamara (2000), language tests have a significant role to play in the lives of many people. The chance of finding an individual who did not encounter any exam is almost none, as almost every person faces the exam, and the practice would have influenced one direction or the other. Shohamy (2001) sets out the test-taking experience that would have been remembered for many years by students or those taking tests. This reflected the effect of the exam on people. Testing functions as a gateway to learning for learners and those who want to work at key moments. Shohamy (2001) points out that it has become the valid tool for inclusion and exclusion. Testing is one of the indicators that educators use to evaluate students' performance and to evaluate their own success in achieving their teaching objectives. Exams reveal the development of the pupils which can provide information on the success of the learning.

There are different forms of strategies used by the examiners during the examinations regardless in foreign or second-language exams. The test methods as procedures that allow examiners to use the characteristics and layout of the test to gain better results in a sample scenario. In Malaysian context, test have been started ever since the pupils in the primary level. English is not the first language for the Melanau pupils but they have to answer the English examination for Ujian Pencapaian Sekolah Rendah (UPSR). Therefore, the study able shed the light on the issue of test-taking strategies in order to help pupils achieve their greatest potential in learning another language despite of English is not their mother tongue.

\section{RESEARCH ELABORATION}

The goal of the research is to study the test-taking strategies of Level 2 primary Melanau, particularly Year 5 pupils, in answering reading comprehension questions English Language Test. This will help shed light on the issue of developing approaches to help them achieve their greatest potential through learning another language, despite the fact that English is not their mother tongue. Through observing the test-taking techniques used, the amount of strategies used for different tasks and the appropriateness of the strategies, it is hoped that an awareness of the process of learning the English language will be established by the learners, particularly the Melanau pupils. 


\section{FINDINGS AND DISCUSSION}

\section{A. Literature Review}

There are two theories mainly underpinning this study. They are Bachman's (1990) and Canale and Swain's (1980). Test taking strategies are known as compensatory where the test takers use them to make up some deficiency in performing the test tasks, the skills require to take the test or both Canale and Swain (1980) are aware that strategic competence put the focus on 'compensatory' and 'coping' methods.

\section{Bachman (1990)}

Bachman (1990) defines strategic competence as a general ability that enables an individual to generate the most effective use of available skills in the execution of a specific task. Strategic skill is recognised as a prevalent capacity to reason for contextual discussion of significance (McNamara, 2000). It includes the ability to assess and implement as part of deciding and carrying out the most effective means of achieving a communicative goal (Bachman, 1990). This differs from those of Canale and Swain (1980), whose idea emphasizes compensating for breakdowns in communication, in other words, compensatory features. Bachman (1990) presents strategic competence is a component of the framework that affect performance on language exam. This shown association between pupils and understanding pupils' processes of how they reach on goal-setting, assessing, planning, and executing in achieving the most effective communicative goal.

\section{Canale and Swain's (1980)}

Canale and Swain (1980) advocate pretty a whole and promising notion of communicative The model has efficaciously dominate the area for distinctly some time. Their proposed model includes three competencies which are sociolinguistic, grammatical and strategic competency. The grammatical competence describes on regulations of grammar which consist of guidelines of grasp of lexical items and rules of morphology, syntax, sentence-grammar semantics and phonology. This included of the information of expressing precisely the literal which capacity of utterances. Next is about sociolinguistic competence which is use of sociocultural and discourse rules. Last past is strategic competence which consist of verbal and non-verbal communication techniques that can be referred to as a method to compensate for breakdowns in discussion owing to performance factors or insufficient expertise. It also relates to the ownership of "coping" strategies when confronted with inadequacies in distinct fields of expertise.

\section{B. Methodology}

This study is a qualitative study which explores and explains the test-taking strategies utilised by participants in a test situation. A qualitative research is descriptive in that the researcher is more concerned with process rather than the outcome or products. In other words, it more to explore the meaning in the context of people's experience and how they make sense of their lives (Merriam 1988). Therefore, the focus in this study is the experience and the mental process that the participants go through while doing a test. It is the process they go through to arrive at their answers which is significance of the study. The researcher interested in discovering the significance that the participants add to their actions, how they view and understand circumstances and their viewpoints on specific issues.

This study answer two research questions. The first part which provides the answer of the RQ1 - What are the test-taking strategies used by Level 2 primary Melanau pupils toward answering reading comprehension questions? The second part provides the answer of the RQ2 - How do the test-taking strategies help in improving English learners answering reading comprehension test? The answers are divided into three subsections; (a) Shorten the time to answer, (b) Increase the motivation of the test taker and (c) Increase the mark obtained for English Comprehension Test. 
There are 6 steps in research procedure for this study. The following figure describes the research procedure in the study.

Figure 1: Research procedure

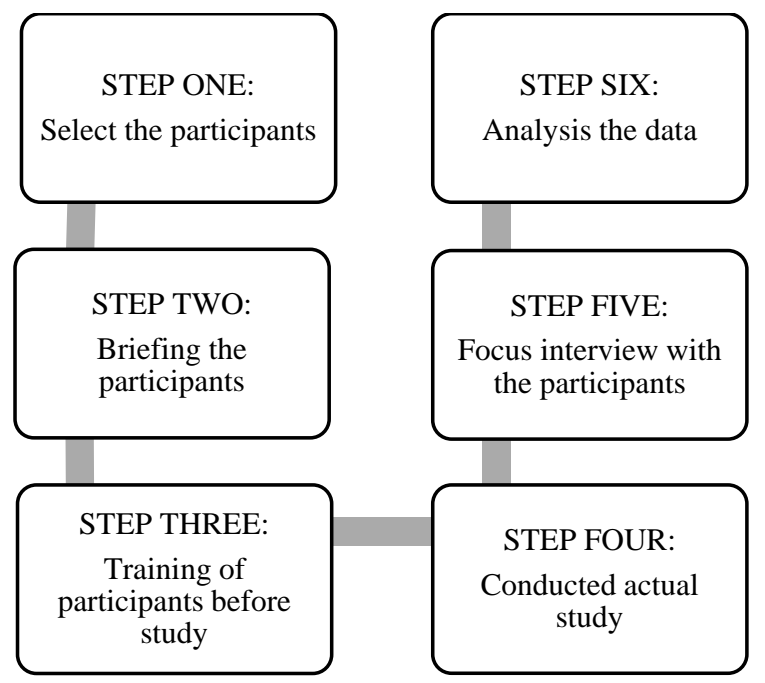

The procedure was begin with selecting 10 participants to involve in this study. 5 of the participants were high level of English proficiency and another 5 is low level of English proficiency. They were selected based on they grade in English comprehension test. Since the researcher had identified the participants, they needed to get brief on what to do during the actual study. The researcher informed the procedure and the reason they have been selected during the session. Any questions from the participants regarding the study also clarified here. The researcher informed that their information and details were confidential, and their name will be known as the pseudonym. The training was conducted for the participants to get them used during the actual study. The researcher made some note any changes that need to rectify. Should there is any amendment, and it will be done right away after the training. The actual study conducted after the training session has done with the participants. Individual interview with the participants was essential to clarify any ambiguities during the actual study. Any questions can be asked directly to the participants if the researcher felt there was doubt during the analysis of data. The second Research Question, which is how do the test-taking strategies help in improving English learners answering reading comprehension test able to be answered during this session as well. The researcher analysed the data taken from the participants.

The processes of data analysis consist of coding the participants, identification and categorization of strategies and transcribe the data.

Coding the Participants

The focus is about the strategies and pupils' level of proficiency. Thus, the participants will be coded according to their proficiency level; the low and high proficiency; male and female. This is to avoid repetition and add clarity to the data analysis process. The participants will be coded as follow:

P - Participant F - Female M - Male

$\mathrm{L}$ - Low proficiency $\mathrm{H}$ - High proficiency

For example; P1FH means Participant 1; Female; High proficiency level of pupils.

Data Transcription

Miles and Huberman (1984) state that qualitative data possess well-grounded, rich and thick descriptions and processes taking place in the local contexts. Meaningful explanations could be obtained besides maintaining the flow of events in the process. Data transcription is the process of transcribing verbal reports verbatim. These verbal reports which were audio-taped consisted participants' retrospective verbal think aloud and playback interview. 
Identification of strategies

There were 31 strategies identified in test-taking strategies. The researcher (x) crossed the strategies at the time TAP is being conducted. Each participant had 25 copies of list of strategies which were for 25 questions allocated in English Paper 013 UPSR. The main purpose of the study is to examine strategies utilised by test-takers in a test situation. The materials used in the study are comprehension English Paper 013 UPSR and checklist. In this study, comprehension English Paper 013 UPSR in 2016 was adopted based on existing multiplechoice comprehension test. The comprehension English Paper 013 as the main instrument to obtain participants' response. This was to ensure that pupils conducting the TAP without worrying which strategies they should cross. The researcher crossed the list for them.

Table 1: List of strategies

\begin{tabular}{|c|c|c|c|}
\hline$(\mathrm{x})$ & No & Code & Strategies \\
\hline & 1. & G & Guesses. \\
\hline & 2. & $\mathrm{CR}$ & Choose the answer through logical reasoning. \\
\hline & 3. & RTP1 & Returns to that section of the text alluded to in the queries. \\
\hline & 4. & LCO & Looks for the answer in chronological order in the passage. \\
\hline & 5. & GUP & Answers the question on the basis of the general understanding of the passage. \\
\hline & 6. & BK & Utilizes previous background knowledge. \\
\hline & 7. & MPQ & Matches words or phrases in the question to similar ones in the passage or the alternatives. \\
\hline & 8. & KW1 & Looks for certain clues or keywords in the passage on the basis of which the answer is made. \\
\hline & 9. & GA & Write a general answer. \\
\hline & 10. & CSP & Copies a sentence or part of it and pastes it as the answer. \\
\hline & 11. & LCP & $\begin{array}{l}\text { Identified the place in the section to which the query related, and then began to search for hints } \\
\text { as to the solution in the background. }\end{array}$ \\
\hline & 12. & $\mathrm{RP}$ & Give an answer focused on the memory of the passage rather than the passage itself. \\
\hline & 13. & CAQ & Clue from answering another question that help answer particular question. \\
\hline & 14. & $\mathrm{~S}$ & Skip the question and return to it later. \\
\hline & 15. & RA & $\begin{array}{l}\text { Stop searching for acceptable options: read alternative choices before find one that was } \\
\text { considered to be right. Don't keep reading the rest of the choices. }\end{array}$ \\
\hline & 16. & EL & $\begin{array}{l}\text { Elimination process: choosing an option, not because it was considered to be right, but because } \\
\text { the others did not seem fair, appeared identical or could not be understood. }\end{array}$ \\
\hline & 17. & EX & $\begin{array}{l}\text { Choosing an exception: suspecting that the alternative was the correct answer because it } \\
\text { represented an exception or had something special about it. }\end{array}$ \\
\hline & 18. & LG & Being influenced by the length of the answer options. \\
\hline & 19. & LO & Being influenced by the location of the answer options. \\
\hline & 20. & $\mathrm{CW}$ & $\begin{array}{l}\text { Common term: selecting an option because it had a term in it that was common - that's been } \\
\text { used all the time. }\end{array}$ \\
\hline & 21. & KW2 & Keyword: arriving at an alternative because it had in it a word that appeared to be a keyword. \\
\hline & 22. & AS & $\begin{array}{l}\text { Association: choosing an option because it had a term in it that elicited a connection with a } \\
\text { phrase in a mother tongue or in another language. }\end{array}$ \\
\hline & 23. & RTP2 & Read the paragraph and make a mental note of where various kinds of information are found. \\
\hline & 24. & RTP3 & $\begin{array}{l}\text { Refer to the passage to check for or affirm the response, rather than relying solely on the } \\
\text { recollection of what was in the paragraph. }\end{array}$ \\
\hline & 25. & RQ1 & $\begin{array}{l}\text { Read the question first, so that the reading of the text is directed at seeking answers to those } \\
\text { questions. }\end{array}$ \\
\hline & 26. & RQ2 & Read the questions second time to make sure the meaning is clearer. \\
\hline & 27. & $\mathrm{OA}$ & $\begin{array}{l}\text { Come up with own answer to the questions before you look at the options that are provided in } \\
\text { the test. }\end{array}$ \\
\hline & 28. & EG & $\begin{array}{l}\text { Make an educated guess based on background knowledge or extra-textual knowledge in making } \\
\text { the guess. }\end{array}$ \\
\hline & 29. & CA & $\begin{array}{l}\text { Ready to change answer appropriately - in the case where new clues are discovered in, say, } \\
\text { another item. }\end{array}$ \\
\hline & 30. & OS & Search an option that seems to different from the others or special. \\
\hline & 31. & $\mathrm{CIO}$ & Use the clues appearing in other items to respond to the item under consideration. \\
\hline
\end{tabular}




\begin{tabular}{|l|l|l|l|}
\hline & 32. & PO & Consider the position of the option among the choices $(\mathrm{a}, \mathrm{b}, \mathrm{c}$, or $\mathrm{d})$. \\
\hline & 33. & $\mathrm{~T}$ & Estimate the time needed for completing the items. \\
\hline
\end{tabular}

\section{CONCLUSION}

The process of reading the test-taking included the use of both the test-taking strategies as well as the reading of the strategy. On this basis, the use of test-taking techniques greatly exceeds that of reading approaches, as the ability of test-takers to answer questions extends beyond their need to fully understand the text. It does not come as a shock that most of the comprehension that test-takers have when reacting to a prescribed reading test is brought about by their responses to the test questions and not by a general understanding based on reading the letter. The study found that the number of test-taking strategies used by high proficiency level of pupils in primary differ from low proficiency level although they were in the same Year 5. The high proficiency used more strategies than the low proficiency of pupils. The high proficiency Melanau pupils used 21 types of strategies, and that is seven more strategy types utilised compared to the low proficiency pupils who used 14 types of strategies in reading comprehension test.

\section{REFERENCES}

[1] Abanomey, A. A. 2002. The effect of texts' authenticity on reading-comprehension test-taking strategies used by adult Saudi learners of English as a foreign language (Doctoral dissertation). ProQuest Dissertation and Theses database.

[2] Abanomey, Abdulaziz. 2002. The effects of texts' authenticity on reading comprehension test-taking strategies used by adults Saudi learners of English as a foreign language. Ph.D thesis. Arizona State University, Arizona.

[3] Allen, J.P. B \& Widdowson, H.G. 1975. Grammar and language teaching. In Allen J.P.B. \& Corder S.P.(ed.). The Edinburgh Course In Applied Linguistics (2) London: Oxford University Press.

[4] Bachman, L. F. \& Palmer, A. S. 1996. Language testing in practice. Oxford: Oxford University Press.

[5] Bachman, L. F. 1990. Fundamental considerations in language testing. Hong Kong: Oxford University Press.

[6] Canale, M. \& Swain, M. 1980. Theoretical bases of communicative approaches to second language teaching and testing. Applied Linguistics 1(1): 1-47.

[7] Cohen, A. D. \& Upton, T. A. 2006. Strategies in responding to the new TOEFL reading tasks. TOEFL Monograph Series. ETS TOEFL.

[8] Cohen, A. D. 1991. Testing linguistic and communicative proficiency: The case of reading comprehension. Languages in School and Society: Policy and Pedagogy (pp. 383-408). https://doi.org/10.1515/9783110869132.383

[9] Ericsson, K. A. \& Simon, H. A. 1984. Protocol analysis: Verbal reports as data. London: The Massachusetts Institute of Technology Press, Cambridge

[10] Goh, H. S. 2009. Using Think-aloud While Reading: What Do Students Think About It. English Language Journal, 3

[11] Green, A. 1998. Verbal protocol analysis in language testing research: A handbook. Cambridge: Cambridge University Press.

[12] Halliday, M.A. K. 1970. Language structure and language function. In Lyons, J. (ed.). New horizons in linguistics. Harmondsworth: Penguin Books.

[13] Hammersley, M. 1996. 'The relationship between qualitative and quantitative research: paradigm loyalty versus methodological eclecticism', in J. T. E. Richardson (ed.) Handbook of Qualitative Research Methods for Psychology and the Social Sciences, Leicester, British Psychological Society.

[14] Hymes, D. 1972. On communicative competence. In Pride J.B. \& Holmes, J. (ed.). Sociolinguistics. Harmondsworth: Penguin Books.

[15] Johnson, K. 1977. The adoption of functional syllabus for general language teaching courses. Canadian Modern Language Review 33(5):667-680.

[16] Kazi, A. M., \& Khalid, W. 2012. Questionnaire designing and validation. Journal of the Pakistan Medical Association, 62(5), 514-516.

[17] Longman, D. G. \& Atkinson, R. H. 1999. Study methods and techniques. Albany, New York: Wadsworth Publishing Company.

[18] Mami, Y. 2007. Think-aloud Protocols and Type of Reading Task: The Issue of Reactivity in L2 Reading Research. Second Language Research Forum. Retrieved from www.lingeref.com/ccp/slfr/pdf

[19] Mckeown, R. G. \& Gentilucci, J. L. 2007. Think-aloud Strategy: Metacognitive Development and Monitoring Comprehension in the Middle School SecondLanguage Classroom. Journal of Adolescent and Adult Literacy, 51 (2).

[20] McNamara, T. F. 2000. Language Testing. New York. Oxford University Press.

[21] Merriam, S. B. 2009. Qualitative research: A guide to design and implementation. San Francisco, CA: John Wiley \& Sons.

[22] Morrow, K. \& Johnson, K. 1977. Meeting some social language needs of overseas students. Canadian Modern Language Review 33(5): 694-707

[23] Nevo, N. 1989. Test-taking strategies on a multiple-choice test of reading comprehension. Language Testing, 6(2), 199-215. https://doi.org/10.1177/026553228900600206

[24] Nikolov, M. 2006. Test-taking strategies of 12-13-year-old Hungarian learners of EFL: Why whales have migraine. Language Learning, 57(1), 1-51. https://doi.org/10.1111/j.0023-8333.2006.00341.x Phakiti, A. (2003). A closer look at the relationship of cognitive and metacognitive strategy use to EFL

[25] Phakiti, A. 2008. Strategic competence as a third-order factor. Language Assessment Quarterly, 5(1), 20-42. https://doi.org/10.1080/15434300701533596 reading achievement test performance. Language Testing, 20(1), 26-56. https://doi.org/10.1191/02655322031t243oa

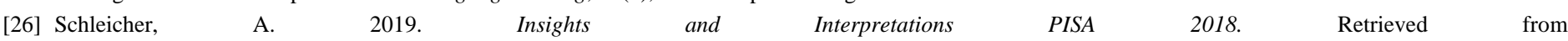
http://www.oecd.org/pisa/PISA\%202018\%20Insights\%20and\%20Interpretations\%20FINAL\%20PDF.pdf

[27] Shohamy, E. 2001. The power of tests: A critical perspective on the uses of language tests. London: Longman

[28] Widdowson, H. G. 1978. Teaching language as communication. Oxford: Oxford University Press.

[29] Wilkins, D.A. 1976. Notional syllabus. London: Oxford University Press. 


\section{AUTHORS}

First Author - Siti Nur'Azmina Binti Ahmad Zainal Abidin, Master's Student (TESL), SK Penibong, Faculty of Education, Universiti Kebangsaan Malaysia, azminawork@gmail.com

Second Author - Maslawati Mohamad, Faculty of Education, Universiti Kebangsaan Malaysia, maslawati@ukm.edu.my

Correspondence Author - Siti Nur'Azmina Binti Ahmad Zainal Abidin, Master's Student (TESL), SK Penibong, Faculty of Education, Universiti Kebangsaan Malaysia, azminawork@gmail.com 